\title{
Effect of the natural progesterone and estradiol on the fertility of cows (bos taurus/bos indicus) inseminated in time fixed in the tropics of Guerrero, Mexico
}

\begin{abstract}
The study was conducted to compare the efficacy of three hormone treatments for synchronization of estrus and artificial insemination in time fixed (IATF) in cows Bos taurus/Bos indicus grazing in the sub-humid tropical conditions. Used 160 records of cows with a body condition 2.5, 3 and 3.5 (scale 1:5) which were subjected to different

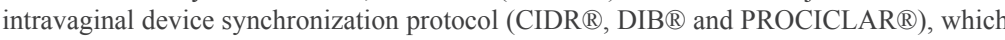
is they applied to day 0 , plus $2 \mathrm{mg}$ of estradiol (BE) benzoate and were retired to the 8th, more the application of cloprostenol $0.150 \mathrm{mg}$, day $91 \mathrm{mg}$ of BE applied, the 10th was the IATF from 52 to 56 hours. Non-return to estrus is Check 21 and 42 days and pregnancy was confirmed by rectal palpation 60 day after the IATF. Evaluated variables: body condition, days and hours of the insemination. The statistical analysis was evaluated with general linear model (GLM) mixed and a significance level of $\mathrm{P}<0.05$. The average pregnancy rate was $33.1 \%(53 / 150)$ for 3 treatments, and $18.75,48.27$ and $31.3 \%$ for treatments 1,2 and 3 respectively. The days postpartum were shorter in treatments based

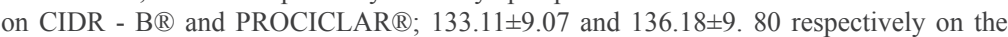
pregnancy rate. The time of insemination at 53 hours has significant effect when using DIB ${ }^{\circledR}$ and PROCICLAR $®$ treatments on conception rate. With respect to the variable body condition was not found significant between treatments on the rate of pregnancy $(p>0.05$ in conditions of tropics of Guerrero, Mexico.)
\end{abstract}

Volume 2 Issue 6 - 2018

\author{
Contreras CF, Cuicas HR, Estrada PE, Gomez \\ VJC, Ávila MB, Mireles MEJ, Jauregui PI, \\ Alonso GJ, Guadarrama TV, Palacios VA \\ Facultad de Medicina Veterinaria y Zootecnia, Universidad \\ Autónoma de Guerrero, Mexico
}

Correspondence: Rosendo Cuicas Huerta, Professor Investigador FMVZ, Universidad Autónoma de Guerrero, Guerrero, Mexico, Email culcas07@hotmail.com

Received: September 14, 2018 | Published: November 26 2018

\section{Introduction}

Livestock in Mexico is one of the most profitable productive activities, currently has $30,833,978$ heads of cattle. Achieving a calf per cow per year in a bovine production system means that, after 365 days of the year, 283 days of the gestation period, the females should be pregnant again after 82 days of calving. Taking into account the 40 to 60 days of recovery of reproductive capacity after childbirth, cows have only one estrus or two to achieve the next pregnancy. The timely detection of jealousy is one of the main factors for good reproductive performance in livestock, considering the failure of this activity, one of the main reasons for the increase in the interval between births in herds. In order to avoid the problem with heat detection, various estrus synchronization protocols have been developed. These treatments are known as fixed-time artificial insemination protocols (IATF). ${ }^{1}$ There are protocols for the synchronization of estrus that can induce the presence of heats in $75-90 \%$ of the animals in a period of 5 days. Without the use of estrus synchronization, only $30 \%$ of estrus detection in animals can be achieved. With the synchronization, a conception range of $65 \%$ is reached, the difference lies in the gestation range, where with synchronization a pregnancy percentage of $49 \%$ is reached and only $21 \%$ without using this protocol. ${ }^{2}$ In this context, the importance of the work is to provide an accessible, reliable and updated source of information about the different techniques of estrus synchronization on the rate of gestation of cows.

\section{Material and methods}

We performed a retrospective study of 160 records of IATF at cow's first service in the region of the Tierra Caliente, Guerrero
Mexico, sub-humid tropical climate and average temperature of 37 ${ }^{\circ} \mathrm{C}$ was used a completely randomized design, for the three protocols synchronization of the data base of a unit of production of cattle, for the 2012-2016 period.

Group 1: We used a natural progesterone-releasing device (CIDR-B $\AA$, impregnated with $1.9 \mathrm{~g}$ of natural progesterone), remained on-site for 8 days, additionally $2 \mathrm{mg}$ of estradiol (ZOOVET, Argentina-NOVAVET, Mexico benzoate were applied ) intramuscular treatment day 0 , day 8 applied $0.150 \mathrm{mg}$ of cloprostenol, (cycling ${ }^{\circledR}$, Lab, ZOOVET, Argentina - NOVAVET, Mexico) via intramuscular, day 9 was applied $1 \mathrm{mg}$ estradiol benzoate (Lab, ZOOVET, Argentina - NOVAVET, Mexico) and the day 10 was IATF (52-56 hours).

Group 2: We used the same protocol, but using DIB ${ }^{\circ}$ (impregnated with $1 \mathrm{~g}$ of natural progesterone, Lab. Syntexvet). Group 3: We used the same protocol, but using PROCICLAR ${ }^{\circledR}$ (impregnated with 750 mg of micronized progesterone, Lab.) Zoovet Argentina - NOVAVET).

The cows were reviewed by observation of not return to estrus at 21 and 42 days, confirmed the gestation by rectal palpation the day after AI 60 , in treatments 1,2 and 3 . Also assessed body condition, days and hours of insemination. The statistical analysis was performed by package SPSS-IBM ${ }^{\circledR}$ view. 20 . The data are presented in percentage $(\%)$, medium $(\dot{X})$ and standard error (EE) with a significance level of $\mathrm{P}<0.05$. The pregnancy rate was seen as a response variable and variables: body condition, days and hours of insemination were considered as independent variables. We used a general linear model (GLM) mixed, whereas as a fixed effect of gestation and as random variable rate treatments. The results were submitted to analysis of 
variance and non-parametric statistics with the Kruskal-Wallis test for the comparison of averages between treatments.

\section{Results and discussion}

The rate of pregnancy of cows Bos taurus/Bos indicus, was 33.1\% $(53 / 150)$ for the 3 treatments and treatment (1,2 and 3$)$ was 18.75 , 48.27 and $31.3 \%$ respectively. Presenting significant difference $(\mathrm{P}<$ 0.05 ) among treatments (Table 1). The fact to have found significant differences between synchronization protocols indicates that treatment 2 a base of DIB $\AA$ and 3 with PROCICLAR $\AA$ are better that 1 a treatment base CIDR ${ }^{\circledR}$ for estrus synchronization in dual purpose cattle Bos taurus/Bos indicus. Comparing the results obtained in this

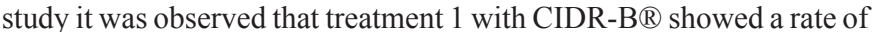

Table I Rate of gestation, body condition, days postpartum and IATF treatment gestation less than that found by Auzmendi et al.,${ }^{2}$ who use CIDR-B ${ }^{\circledR}$ $+1 \mathrm{mg}$ of BE, noting the $32.1 \%$ of gestation, while using DIB ${ }^{\circledR}+0.5$ $\mathrm{mg}$ of EC found the $23.7 \%$. In contrast, Gutierrez et al., ${ }^{3}$ obtained a 75 and $40 \%$ of pregnancy in calves by using device CRESTAR ${ }^{\circledR}$ and DIB ${ }^{\circledR}$ respectively, which is superior to that found in this study. In this regard, Perez (2007) obtained a $54.8 \%$ of gestation in heifers using devices CIDR $®$ new. While Flores et al., ${ }^{4}$ obtained a $56.5 \%$ of gestation using CIDR ${ }^{\circledR}+\mathrm{BE}$ and $47.8 \%$ using CIDR ${ }^{\circ}+\mathrm{GnRH}$. In regards to variable body condition evaluated in this study, significant between treatments on the pregnancy rate was found $(\mathrm{P}>0.05$, Table 1 and (Figure 1). In support of these findings, Gastelum, (1998) evaluated body condition on conception rate and got no significant differences for a body condition of the cows postpartum of 2.5, 3 and 3.5 with 47,53 and $62 \%$ gestation rate respectively.

\begin{tabular}{llllll}
\hline Treatment & $\mathbf{N}$ & \% Conception rate & $\mathbf{C C}$ & PP(Days) & IATF(Hours) \\
\hline I & 16 & $18.75^{\mathrm{a}}$ & $2.7 \pm 0.44^{\mathrm{a}}$ & $136.18 \pm 9.80^{\mathrm{a}}$ & $56.00 \pm 1.43^{\mathrm{a}}$ \\
$(\mathrm{CIDR}-\mathrm{B})$ & & & & & \\
2 & 29 & $48.27^{\mathrm{b}}$ & $2.7 \pm 0.31^{\mathrm{a}}$ & $162.34 \pm 10.55^{\mathrm{b}}$ & $53.79 \pm 1.42^{\mathrm{b}}$ \\
$(\mathrm{DIB})$ & & & & & \\
3 & 115 & $31.3^{\mathrm{c}}$ & $2.6 \pm 0.44^{\mathrm{a}}$ & $133.11 \pm 9.07^{\mathrm{a}}$ & $53.80 \pm 1.41^{\mathrm{b}}$ \\
(PROCICLAR) & & & & & \\
\hline
\end{tabular}

$\dot{X} \pm$. BC. Body condition; DP: Days postpartum; IATF: Artificial insemination in time fixed.

a, b, c: $P<0.05$.

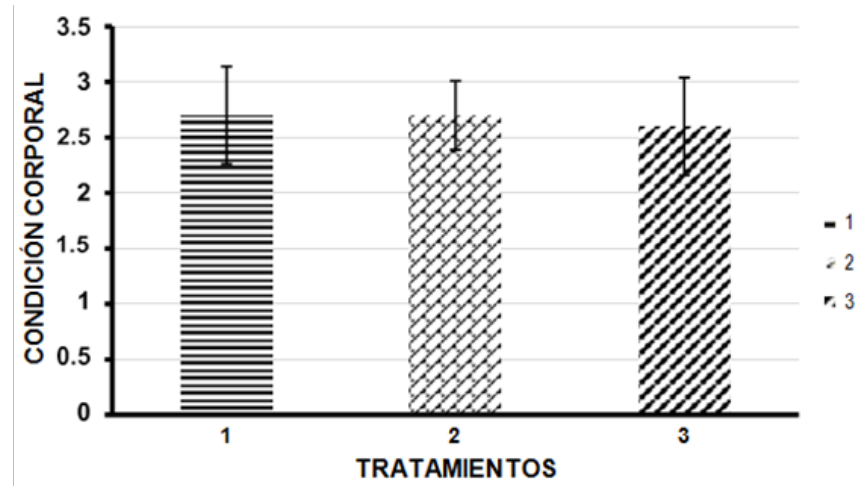

Figure I Average body condition with different treatments of synchronization of estrus $(\dot{X})$ and error $(E E)$ standard.

On the other hand, in the present study effect was observed of the days between treatments 1 with CIDR-B ${ }^{\circledR}$ and 3 with PROCICLAR $\AA$ in conception rate and only treatment 2-based $\mathrm{DIB} \otimes$ were longer days postpartum $(\mathrm{P}<)$ 0.05, Table 1 and (Figure 2). reported by Sepulveda et al., ${ }^{5}$ They mention that you cows synchronized with CIDR-B ${ }^{\circledR}$ were inseminated in average 97 days postpartum and DIB ${ }^{\circledR} 70$ days post-partum, there are significant differences $(\mathrm{P}<0.05)$ between both groups. In the variable evaluated hours of IATF, significant difference was observed in the present study $(\mathrm{p}<0.05)$ in favor of treatments 2 (DIB ${ }^{R}$ ) and treatment 3 (PROCICLAR ${ }^{\circledR}$ ) with 53.79 and 53.80 hours respectively on treatment 1 based on of CIDR-B ${ }^{\circledR}$ of 56 hours, that is to say that treatments 2 and 3 influence the gestation rate of Bos turus/Bos indicus cattle inseminated at fixed time (Table 1). In this sense Cesaroni et al., ${ }^{3}$ report a significant difference of more than $5 \%$ in the IATF hours for Bos indicus cows. In another study conducted by Vallerga et al., ${ }^{6}$ they obtained a significant difference in the pregnancy percentages obtained in the different 52 and 56 hours of IATF schedules. Also Salgado, et al., ${ }^{7}$ in a study of IATF using PROCICLAR $\AA$ + equine chorionic gonadotropin (eCG) obtained a $29.6 \%$ of gestation, higher figure than that found in this work, but with application of eCG. ${ }^{8-15}$

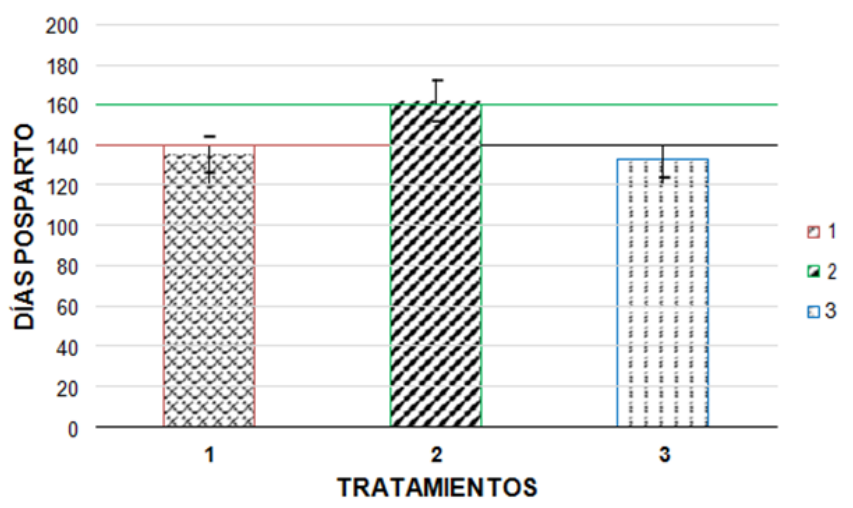

Figure 2 Days Postpartum Estrus synchronization treatment medium $(\dot{X})$ and error (EE) standard.

\section{Conclusion}

Under conditions of dry tropics of Guerrero, the gestation rate in Bos taurus/Bos indicus cows treated with intravaginal devices are for CIDR (18.8\%), DIB ${ }^{\circledR}$ (48.3\%) and PROCICLAR ${ }^{\circledR}$ (31.3\%). The condition of the cattle has no effect. The postpartum days were shorter in the treatments based on CIDR-B ${ }^{\circledR}$ and PROCICLAR ${ }^{\circledR}$ on the gestation rate. And finally, the time of insemination at 53 hours has a significant effect when using the DIB $\AA$ and PROCICLAR $\AA$ treatments on the pregnancy rate in Bos taurus / Bos indicus cows. 


\section{Acknowledgments}

None.

\section{Conflicts of interest}

The author declares there is no conflicts of interest.

\section{References}

1. Cutaia L, Veneranda G, Tríbulo R. Programas de Inseminación Artificial a Tiempo Fijo en Rodeos de Cría: Factores que lo Afectan y Resultados Productivos". $5^{\circ}$ Simposio Internacional de Reproducción Animal. Huerta Grande, Córdoba. 2003;119-132.

2. Auzmendi M, Vater A, Cobodevila J. Tasas de concepción en rodeos lecheros utilizando progesterona y diferentes sales de estradiol. Tesis de Licenciatura. Facultad de Ciencias Veterinarias, UNCPBA. 2015.

3. Cesaroni G, Butler HM, y Durand MJ. Evaluación del uso de dos ésteres de estradiol sobre la tasa de fertilidad a la iatf en vacas secas, tratadas con un dispositivo intravaginal con progesterona méds. Veterinarios Taurus. 2007;9(36):12-18.

4. Flores AM, Enríquez EB, Anchondo GA. Use of GnRH or estradiol benzoate in heifers synchronized with progesterone and PGF2a. Technoscience Chihuahua. 2013;8(1):17-24

5. Sepulveda N, Risopatrón J, Rodríguez F. Fertility in dairy cattle associated with jealousy and insemination synchronization in time fixed using GnRH and PGF2a. Faculty of agriculture and forestry Sciences 2003.

6. Vallerga J, Sarramone CG, Dick A. Study of fertility obtained in heifers detected in estrus by painting and inseminated at different moments and its relationship to the follicular State. Faculty of Veterinary Sciences, UNCPBA. 2016.

7. Salgado O, Gonzales TR, Simanca JM. Inseminación fixed in brahman cows while nursing. Revista MVZ Eurostars. 2007;12(2):1050-1053.
8. Dejarnete JM, House RB, Ayars WH, et al. Synchronization of stress in postpartum beef cows and virgin heifers using combinations of melengestrol acetate, GnRH, and PGF2a. Journal of Animal Science. 2004;82(3):867-877.

9. Gutiérrez M, Bautista A, Quinteros R. Protocols of artificial insemination in time fixed (IATF) and its effect on the release of $\mathrm{LH}$ and conception rate in calves kept in humid tropical environment. SPERMOVA. 2005;1(5):29-32.

10. Pérez J. Rate of pregnancy in cows with intra-vaginales devices CIDR new and used two or three times for seven days, in the Hacienda Santa Elisa, El Paraiso, Honduras. Thesis for the title of agronomist at the undergraduate academic degree. Zamora, Honduras. 2007.

11. Guadarrama TV. Natural progesterone and gonadotropin equine chorionic on pregnancy in cows anestric cebu by Swiss with different body condition. Thesis for the veterinarian and Zootechnician title in the undergraduate academic degree. Faculty of veterinary medicine and animal husbandry does not 1.2002.

12. Gastelum PLE, Pedroza PD. Synchronization of estrus in heifers with prostagenos or prostaglandins and a combination of both. First meeting of scientific, forestry and farming. Mexico. 1998.

13. Palacios VA, Araujo BF. Effect of one or two doses of semen in artificial insemination in time fixed on the rate of gestation in cows Brahman treated with intravaginal device (DIV) new or used more injectable progesterone. Thesis for the veterinarian and Zootechnician title in the undergraduate academic degree. Faculty of veterinary medicine and animal husbandry does not 1.2012.

14. Pérez J. Tasa de preñez en vacas con dispositivos intra-vaginales CIDR nuevos y usados dos o tres veces por siete días, en la Hacienda Santa Elisa, El Paraíso, Honduras. Zamora Honduras. 2007. p. 1-21.

15. Sergio BD, Figueroa SF. Determination of cyclicity and assessment and body condition in a program of IATF Mercedes-Corrientes breeding cows. Facultad de Ciencias Agropecuarias. Institute of Animal production. Cordoba. 2014 